\title{
Architectural and Structural Analysis of the Tamang Houses in Haku, Rasuwa
}

\author{
Jonas Raphael Häberle, Jagat Kumar Shrestha \\ Department of Civil Engineering, Pulchowk Campus, Institute of Engineering, TU, Nepal \\ Corresponding author: jagatshrestha@ioe.edu.np
}

Received: Sep 28, 2018

Revised: Dec 10, 2018

Accepted: $\operatorname{Dec} 15,2018$

\begin{abstract}
This paper provides a summary of an architectural and structural analysis of traditional Tamang houses in Haku, Rasuwa and the best methods for integrating seismic resistant features and cultural preservation in the recovery after the $2015 \mathrm{Nepal}$ earthquakes.
\end{abstract}

Key words: Architectural analysis, structural analysis, architectural heritage preservation

\section{Introduction}

The Haku community, living in Haku VDC, Rasuwa was severely affected by the two major earthquakes that occurred in Nepal on 25th April and 12th May 2015. This community is living in central Rasuwa, Nepal and has a rich heritage of Tamang culture. Very little architectural research, if any, has been carried out in this region to record and document their unique architecture. Even before the earthquake, the community was already undergoing economic and social changes that posed a threat to the preservation of their indigenous culture and architectural heritage. The destruction of nearly all the houses in Haku in the 2015 earthquakes has only increased this threat. Many in the community now prefer houses built with modern building techniques (e.g. steel frame or cement and rebar structures) over houses built with their traditional building techniques thus threatening the architecture heritage for the region.

Many stakeholders agree that it is important to rebuild houses destroyed in the earthquake according to the architectural heritage of the community. Dr. Prabin Manandhar, the Country Director of Luther World Federation said it with these words: "Reconstruction is not only about rebuilding homes, but also about rebuilding heritage. Culture is the heart of our nation" [4]. This paper provides an overview of the architectural analysis and the structural analysis of the Tamang houses found in Haku as well as recommendations on how to integrate seismic resistant techniques into the traditional houses towards the preservation of their architectural heritage and a conclusion of the paper.

\section{Architectural Analysis}

The houses found in Haku can be classified as Tamang houses with a similar architectural style also found in other Tamang communities throughout northern Nepal. The Tamang people are among the people groups that got hit the hardest by the 2015 earthquakes [3]. Their traditional 
houses are built with stone and wood. Most houses in Haku are directed towards the South-East to catch sunlight as it rises in the East and shines throughout the day. The South-East walls are made entirely out of wood. The other load bearing walls are composed of dry stone masonry. The average size of a traditional house in Haku is 5-9m long, $5-7 \mathrm{~m}$ wide and 2 stories high. The ground floor is mainly used for livestock and cattle. In the upper floor, the family to lives, eats and sleeps in one big common area around a fire place. The attic is used as storage for agriculture produce, tools and other belongings.

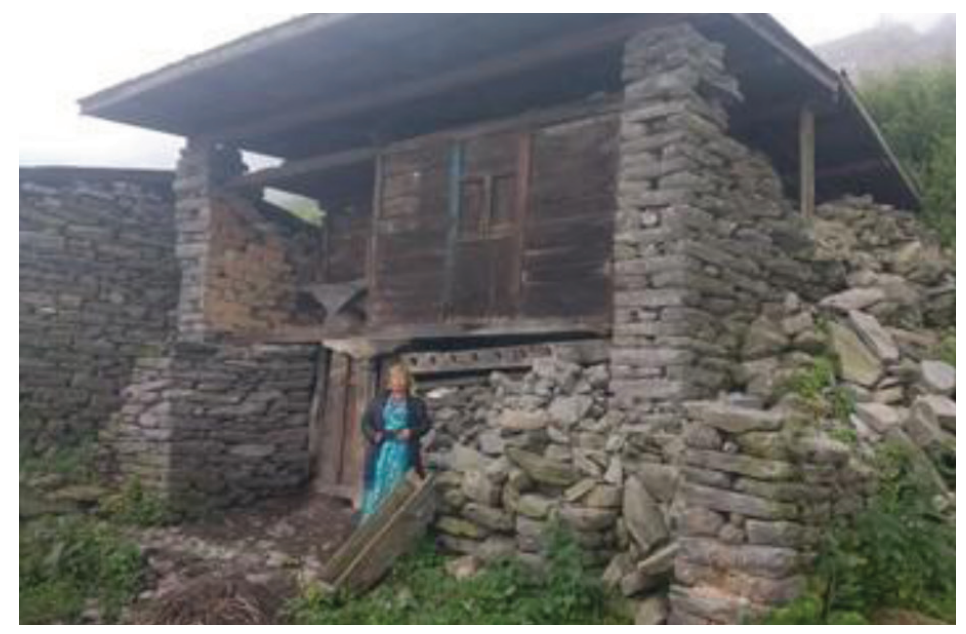

Fig. 1: A Tamang woman from Haku standing in front of her broken house in Tulo Haku, Rasuwa

Another unique architectural feature of the traditional Tamang houses found in Haku is the formation of row houses lined up into the orientation of the hill. The houses are built right next to each other, many of them sharing their side walls with each other. This reduces the time-consuming work of cutting the massive stones by hand that are needed for the side walls for one family by half. It is also an expression of how closely the community lives with each other and how closely they are related to each other. As the families have expanded over the years, houses were added to the sides of the existing houses and the picturesque Tamang settlement grew house by house.

\section{Structural Analysis}

House foundations in Haku are built on rocky and sandy soil. Since the houses are built into the steep slopes, most foundations were built with a different foundational depth in the front than in the back. The side and back walls of the houses are made from dry stone masonry. The walls are constructed with a thickness of $700 \mathrm{~mm}-800 \mathrm{~mm}$ using local hand cut stones. The wall's thickness makes the structure very heavy and sturdy. The stones are usually shaped relatively straight on the outside. The hand cut stones are stacked up dry on top of each other without any mortar to bind the stones together. Since the stones are not perfectly straight and are not settled into each other through mortar layers, the walls are structurally very vulnerable to horizontal forces causing the wall to fall apart easily.

A further structural weakness is the lack of elements that tie the walls together both horizontally and vertically. The horizontal timber beams of the front wall and at the openings have been found to be the only elements that tie the structure together. In many houses, it was observed that the wall corners lost their structural integrity and started bending outwards or that the long walls collapsed 
in the middle of their span during the earthquakes. The back walls are buried into the earth's slope in most cases. This protected the back walls from collapsing and served as a structural strength of the houses.

The houses have timber walls on the front side of the house. Structurally, those timber walls showed great resistance to the horizontal forces during the 2015 earthquake. Timber from pine trees as found in Haku have a tensile strength of approx. $20-40 \mathrm{~N} / \mathrm{mm} 2$ [5]. This tensile strength keeps the structure flexible and resistant to collapsing during horizontal forces in seismic movement. In the picture below, it is shown how the timber front wall and the timber structure of a house kept the roof from collapsing while the dry masonry walls on its sides collapsed entirely. Since those timber front walls add a very unique architectural feature and proved to strengthen the structure during seismic movement, the community is strongly advised to continue implementing this feature in the rebuilding of their houses.

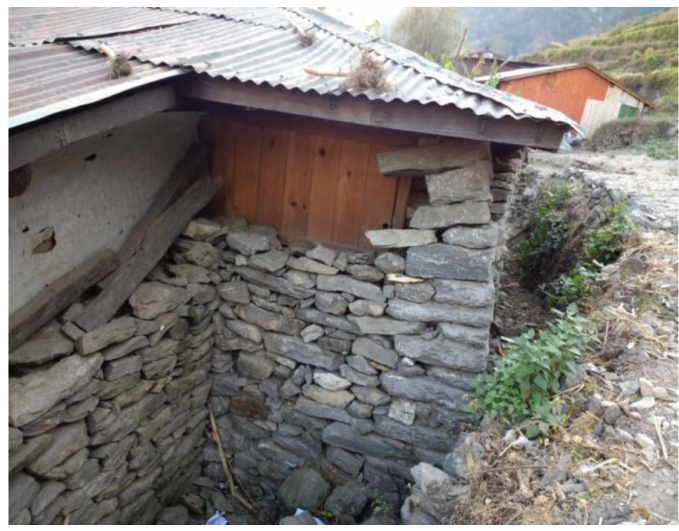

Fig. 2: Corners of wall collapsed due to lacking mortar and horizontal banding

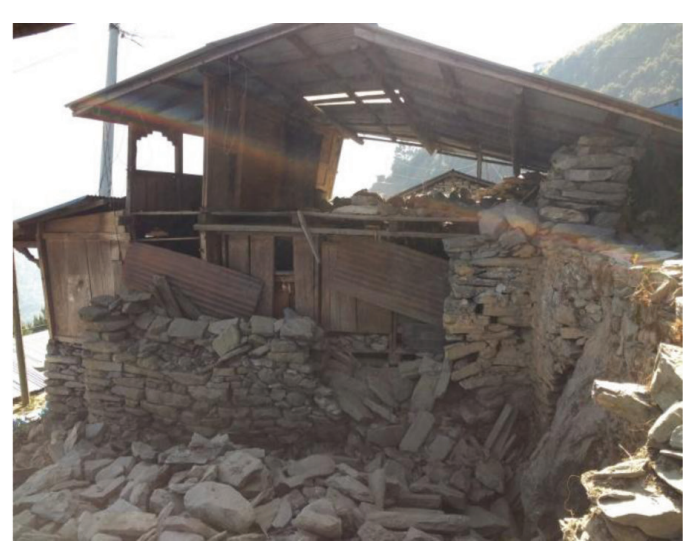

Fig. 3: A house in Haku which kept the roof from collapsing due to its wooden structure of the front wall, floors and buried back wall

The floor between the ground and upper floor is constructed with local timber. The given dimensions of the timber beams used for the floor have a proper thickness of $100 \mathrm{~mm}-150 \mathrm{~mm}$ and are spaced evenly at about $1000 \mathrm{~mm}$ center to center. The boards have a thickness of $25 \mathrm{~mm}-35 \mathrm{~mm}$. The timber floors strengthen the structure of the house. Due to its tensile strength and flexibility, they act as a horizontal binding on the top of the ground floor walls. It is important to ensure proper connection between the timber floor construction and the stone walls. Another interesting structural element in the house's interior is traditional heavy-duty timber furniture. Along the inside of the stone walls, racks and cabinets to store kitchenware and clothes cover much of the inside walls. Some houses even have a complete wooden cover on the inside of the masonry wall. This provides an insulation layer that keeps the inside of the house warm. Additionally, this wooden cover also proved to add a strengthening structural element during the earthquakes in 2015. The furniture is made from 25$35 \mathrm{~mm}$ thick timber boards. In many cases, the wooden interior furniture and wall cover helped to keep the roof from collapsing while the stone wall on the outside collapsed. The wooden cover on the inside also protected the people inside the house from injury since the outside stones could only fall outwards and not inwards. 


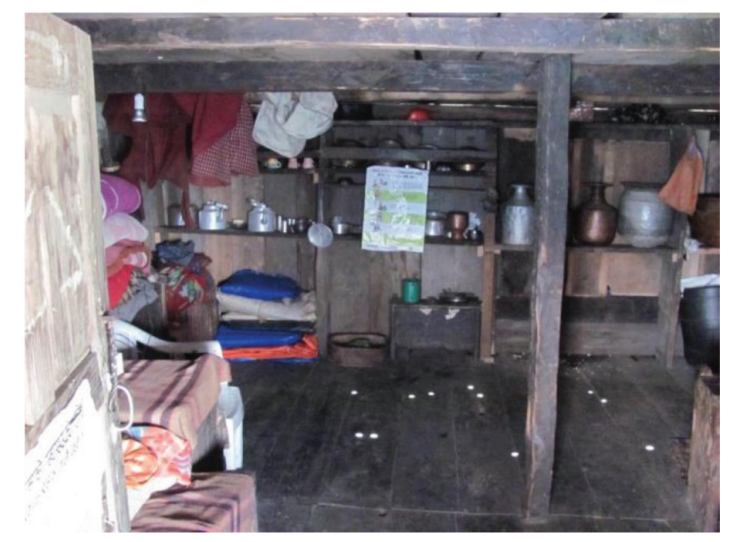

Fig. 4: Interior of a traditional house in Haku with timber furniture and timber floor

The gables of the traditional Tamang houses are made from dry stone masonry. Together with the side walls, they form one large structural element. Yet, the gables are listed here as a separate structural element, because they were identified as the greatest structural weakness during the seismic movement. In most cases, the dry-stone masonry gables collapsed in the 2015 earthquakes. Therefore, it is recommended to find ways to strengthen the gables as a structural element in future houses. One of those ways would be to exchange the stones with timber boards to construct the gables of the house.

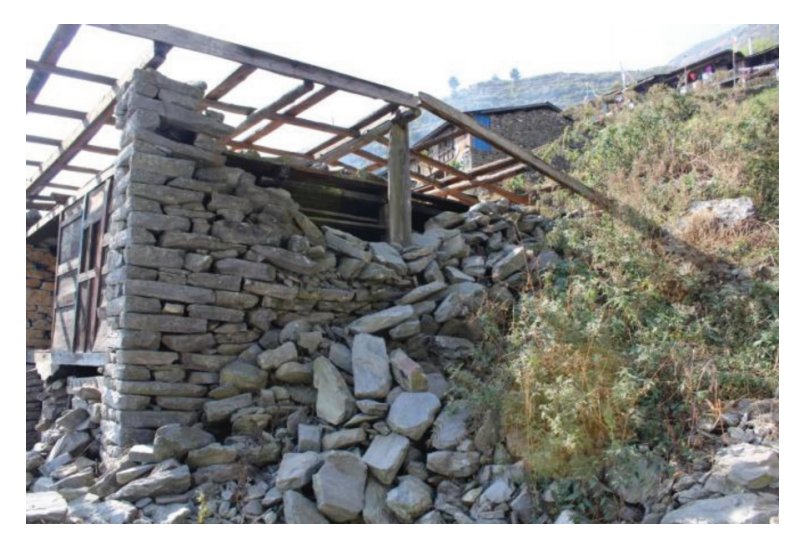

Fig. 5: A picture of a house in Haku where the dry-stone gable collapsed

The roof structure of Tamang houses in Haku is traditionally made from a timber frame and covered with thin wooden shingles or more recently with corrugated galvanized iron (CGI) sheets. Some houses were identified to have supporting joist beams on the bottom of the roof structure. These houses (with joist beams) had a lower collapse rate in the 2015 earthquakes. Therefore, the joist beams have been identified as important for the strength of the roof structures and are recommended to be built into future houses as well.

\section{Recommendations}

\subsection{Foundation}

Based on the findings of this study, the author recommends following the minimal requirements given in the DUDBC design catalogue for the foundation of the new houses in Haku. The requirements 
given by the DUDBC are as listed on page 67 in the design catalogue. "The foundation trench shall be of uniform width. The foundation bed shall be on the same level throughout the foundation in flat area. The depth of footing should not be less than $800 \mathrm{~mm}$ for one storey, $900 \mathrm{~mm}$ for two stories. The width of footing should not be less than $600 \mathrm{~mm}$ in medium soil condition. As depend on soil condition" [2].

\subsection{Mortar}

To increase the binding between the stones, the author recommends using either mud or concrete mortar in between the stone layers in the construction of the foundation and walls of the new houses. Concrete mortar is preferred, because the local mud identified in Haku did not seem to have a sufficient quality. In any case, mud and cement mortar should not be mixed in the same wall (this was identified as one of the practices of local craftsmen to reduce costs) as mixing the mud and the cement will dry out the water content in the cement and prevent the cement mortar from setting properly. This will then prevent the stones from binding together sufficiently. It is recommended to stop this practice. The cement mortar should be mixed with a ratio of 1:4 (Cement: Sand) in order for the joints to connect the massive stone walls and increase their resistance to future seismic activity.

Since the usage of cement mortar on the outside walls will have a noticeable effect on the traditional architecture, the joints should be kept with the minimum thickness of $10 \mathrm{~mm}$ and should be washed off or hidden as much as possible on the outside wall. The remaining mortar can be washed off as soon as possible on the outside of the joints using old cloth rags or plastic bags with water.

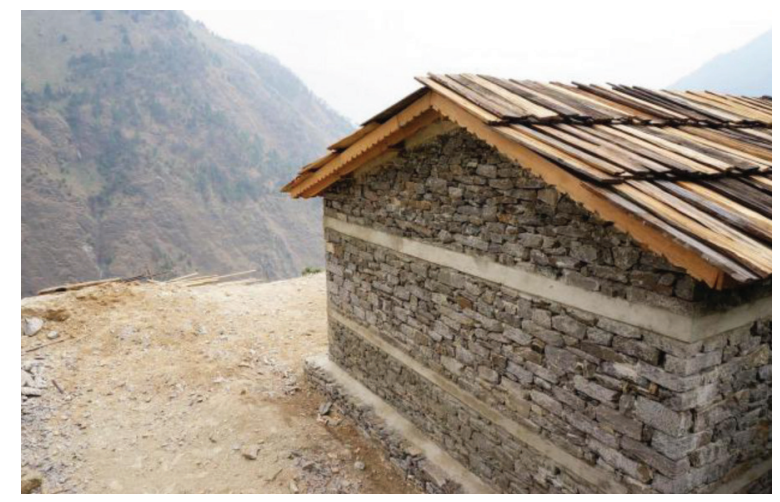

Fig. 6: New house built in Gatlang village with horizontal RCC banding and cement mortar

It still includes a traditional clean stone look on the outside of the wall and a traditional roof covered with wooden shingles [1].

\subsection{Through-stones and Interlocking Masonry}

The side and back walls should continue to be constructed with local stones. A high percentage of the old, traditional stones of the destroyed houses in Haku can be reused for the rebuilding of the new walls to reduce the costs for the new buildings and to incorporate the traditional materials into the new houses. The following structural requirements given by the DUDBC should be followed: "Masonry should not be laid staggered or straggled in order to avoid continuous vertical joints. At 
corners or wall junctions, through vertical joints should be avoided by properly laying the masonry. It should be interlocked. Through-stone of a length equal to the full wall thickness should be used in every $600 \mathrm{~mm}$ lift at not more than $1.2 \mathrm{~m}$ apart horizontally. The minimum width of wall is 350 $\mathrm{mm}$ for one-storey and two-storey [2].

\subsection{Horizontal Banding}

The author recommends that horizontal bandings should be added as a structural element to the traditional house structures. According to the DUDBC, the following five bandings are required: plinth band, sill band, lintel band, stitch and roof band. The bandings are recommended as reinforced concrete bands for stone masonry and cement mortar structures (SMC). However, this structural requirement of specific types of bandings conflicts with the traditional architecture. Therefore, the new houses should focus on minimizing the amount of concrete needed in the reinforced concrete bands while still maintaining the structure's strength as much as possible.

One way to reduce the cement and re-bar in bandings without compromising the structural resistance to seismic movement would be to shorten the height of the structure. With this change, the roof and the lintel band could be combined in the same band. This would then allow the roof to start right on top of the door and window openings. Additionally, the stitch band could be reduced to only one band if the windows have a maximum height of $1400 \mathrm{~mm}$. The required stitch bands (every $700 \mathrm{~mm}$ ) would be reduced to only one banding at each corner and T-Junction within the wall. A second way to preserve traditional architecture while still integrating the required banding is the use of timber banding instead of reinforced concrete banding. The DUDBC design catalogue allows timber banding to be used with stone masonry and mud mortar (SMM) structures: "Where reinforced concrete is not available, timber bands and stitches could be used" (2). Therefore, another recommended option would be to use timber for the plinth band, sill band, stitch band and a combined lintel/roof band. The wooden banding should be constructed properly as shown on the drawing given by the DUDBC design catalogue on page 141. Timber can also be used for the vertical band at the corners and T-junctions. It is recommended to use timber for both the horizontal and vertical bands to avoid complications with forming a proper connection of re-bar and timber reinforcement.

Based on their experience, some house owners of the local community argue that the plinth level band could be destroyed within a shorter amount of time than the rest of the structure, because of its exposure to rain. To avoid this potential risk, another possibility would be for the plinth level band to be constructed with reinforced concrete instead. This would only minimally interfere with the traditional architecture. In this case, it is also recommended to use re-bar for the vertical reinforcement within the corner and T-Junction, since they could create a strong connection between the wall structure and the plinth level banding as well as to the bottom of the foundation.

\subsection{Timber Gable}

The author recommends building the gable from timber and using local wooden planks of $25 \mathrm{~mm}$ thickness to cover the gable areas. To protect the gable areas from rain, there needs be a sufficient overhang from the roof over the wall of at least $600 \mathrm{~mm}$. Additionally, the timber should be treated with "coal tar or any other preservative to prevent timber from being decayed and attacked by insects" (2). 


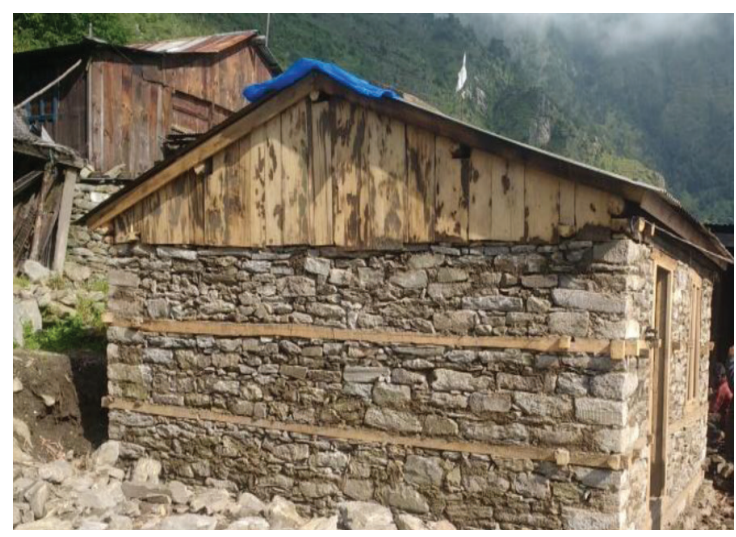

Fig. 7: Newly constructed house in Haku with timber gables and timber bandings

\subsection{Roof Structure}

The author recommends the roof structure to be constructed with smaller spacing between the rafters and purlins as is done traditionally. It is also recommended to use joist beams to construct a triangle between the rafters and the joist bands. This structural triangle offers stability and does not create any additional horizontal forces on the top of the walls in the case of seismic movement. The main purlin should have the dimensions of $100 \mathrm{~mm} \times 200 \mathrm{~mm}$ and the rafters should have dimensions of $90 \mathrm{~mm} \times 150 \mathrm{~mm}$ with spacing from center to center of $1000 \mathrm{~mm}$. The purlins $(75 \mathrm{~mm}$ $\mathrm{x} 75 \mathrm{~mm}$ ) should be placed with spacing from center to center of $600 \mathrm{~mm}$. Preferably, the roof should be covered with wooden shingles made from local timber to conform to traditional building techniques and preserve the architectural heritage. The structural construction of the roof should also follow the minimum requirements given by DUDBC [2].

\section{Conclusion}

The following architectural and structural elements of the traditional houses in Haku are identified as strengths and it is recommended to continue integrating these elements as houses are rebuilt:

- Row houses that line up horizontally along the slope of the hill

- Two-storey houses that are built into the slope of the hill

- Timber walls with balconies towards the front of the house

- Timber doors and windows with decorative carvings

- Timber floors between the first and second floor

- Interior timber furniture and wall coverings

- Timber roof structure with wooden shingles as roof covers

The following structural elements have not been traditionally used in Haku, but are recommended to be included to increase the resistance of the structures to seismic movement:

- Sufficient depth of foundation

- Cement mortar between the stone masonry walls

- Through-stones and interlocking masonry

- Horizontal timber bandings on plinth, stich, sill and lintel/roof level

- Gable construction with local timber boards

- Roof structure with joist beams and smaller spacing between rafters and primers 
130 Architectural and Structural Analysis of the Tamang Houses in Haku, Rasuwa

\section{References}

[1] Architecture in Development (2017), Le Village Noir. Gatlang.

[2] DUDBC (2015), Design Catalogue for Reconstruction of Earthquake Resistant Houses. Kathmandu: Department of Urban Development and Building Construction.

[3] Emergency Architects. 2016. Study of habitat typologies and Solutions for their seismic reinforcement. Kathmandu.

[4] Lutheran World Federation (2016), Rebuilding homes and heritage in Nepal one year on. Kathmandu.

[5] Schneider, Klaus-Juergen (2010), Bautabellen fuer Ingenieure. Colone: Werner Verlag. 